\title{
SROI with Assurance Can Help Contributors Distinguish Hypocritical Organizations from Genuine NFPs
}

\author{
Fuminobu Mizutani ${ }^{1 *}$ \\ ${ }^{\text {I} A s s o c i a t e ~ P r o f e s s o r, ~ D e p a r t m e n t ~ o f ~ B u s i n e s s ~ A d m i n i s t r a t i o n, ~ K a n t o ~ G a k u i n ~ U n i v e r s i t y, ~ Y o k o h a m a, ~ J a p a n ~}$
}

\begin{abstract}
The American film Poverty, Inc. alerted citizens to the fact that some "not-for-profit" organizations impair public benefit and seek profit. To avoid to contributing to such hypocritical organizations, this paper considers the possible use of SROI. SROI is an accounting concept used to evaluate NFPs. There is a problem called overhead aversion among contributors. It is hypothesized that spreading the use of assurance on SROI will face this problem. If so, a measure against this is necessary. This paper builds its theory on the existence of negative SROI as a tool to distinguish hypocritical organizations from genuine NFPs from the perspective of welfare economics, and argues that, theoretically, SROI can be negative. This paper then uses a questionnaire-based survey and conducts various statistical analysis to show that disclosure of SROI with assurance is practical. Nevertheless, it is also shown that assurance on SROI faces overhead aversion, a measure against which is provided by an influential paper. Spreading the use of SROI with assurance will trigger a shift from contribution to hypocritical organizations to contributions toward genuine NFPs. Such a shifts in contributions may also improve welfare. The main conclusion of this paper is that SROI with assurance can help contributors distinguish hypocritical organizations from genuine NFPs.
\end{abstract}

\begin{tabular}{|c|c|c|c|}
\hline \multicolumn{4}{|l|}{ Keywords: } \\
\hline \multicolumn{4}{|l|}{ SROI; } \\
\hline \multicolumn{4}{|l|}{ NFP; } \\
\hline \multicolumn{4}{|c|}{ Accounting; } \\
\hline \multicolumn{4}{|l|}{ Assurance; } \\
\hline \multicolumn{4}{|l|}{ Hypocrisy. } \\
\hline \multicolumn{4}{|c|}{ Article History: } \\
\hline Received: & 04 & November & 2020 \\
\hline Revised: & 14 & January & 2021 \\
\hline Accepted: & 21 & January & 2021 \\
\hline Published: & 01 & February & 2021 \\
\hline
\end{tabular}

\section{1- Introduction}

This paper aims to explain that Social Return on Investment (SROI) with assurance can help contributors distinguish hypocritical organizations from genuine not-for-profit organizations (NFPs), and that distinguishing hypocritical organizations from genuine NFPs will prevent impairment to public benefit. NFPs are nonprofit, independent organizations that promote public benefit, a concept similar to welfare. In economics, it is widely known through Mankiw (2016) that NFPs have positive externality [1]. In contemporary Italy, many NFPs contribute to welfare.

Poverty, Inc. is an American film released in 2014 that won the Templeton Freedom Award in 2015. This documentary revealed that some "not-for-profit" organizations impair welfare, and that this impairment is sustained by contributors to such organizations [2]. Thus, in order to maximize welfare, contributors should distinguish such hypocritical organizations from genuine NFPs and avoid contributing to the latter.

This paper assumes that hypocrisy impairs welfare. Independence may not decide if an organization that calls itself a NFP is hypocritical or not. For an organization that calls itself a NFP, profit-seeking is a factor of hypocrisy. Determining whether an organization is actually profit-oriented is relatively easy if contributors check the cash flow of the organization. If the organization makes dividends, regardless of what it calls itself, it is profit-oriented. However, not all organizations that call themselves NFPs and are actually profit-oriented are necessarily hypocritical, because some such

* CONTACT: Fuminobu@kanto-gakuin.ac.jp

DOI: http://dx.doi.org/10.28991/esj-2021-01253

(C) 2021 by the authors. Licensee ESJ, Italy. This is an open access article under the terms and conditions of the Creative Commons Attribution (CC-BY) license (https://creativecommons.org/licenses/by/4.0/). 
social enterprises may in fact promote welfare. To be profit-oriented is a necessary condition of being a hypocritical organization, but this alone is not sufficient. Thus, contributors should consider whether an organization that calls itself a NFP promotes welfare, which is more difficult.

The second section is devoted to a literature review. The third section builds a theory to distinguish hypocritical organizations by SROI with assurance. The forth section explains the methodology adopted in this paper. The fifth section show results using statistical analysis. The sixth section interprets the results. Finally, this paper shows its conclusion.

\section{2-Literature Review}

An emerging accounting concept called SROI solves the difficulty mentioned above. Green et al. (2020) regards SROI as a technology and Bellucci et al. (2019) is paper devoted to SROI by accounting scholars in Italy [3, 4]. There is some prior research aimed at determining which organizations are hypocritical according to SROI. Although McElwee and Smith (2015) advocate the use of negative SROI to uncover profit-oriented entities that impair welfare, they do not explain the existence of negative SROI from the perspective of welfare economics [5].

Gneezy et al. (2014), published in the widely read Science, examines accounting at NFPs and promotes effective activities within them. It is worth noting that they were supported by the John Templeton Foundation, which, like the Templeton Freedom Award, is named after Sir John M. Templeton [6]. Organizations which are pursuing Sir Templeton's will promoted effective activities by NFPs through Poverty, Inc. and Gneezy et al. (2014) in that period.

Contributors used to look not at SROI but at overhead cost ratio to decide which organization to contribute to. However, recent research, including Gneezy et al. (2014) revealed that overhead cost ratio is not suitable for such judgement. Gneezy et al. (2014) insists that sufficient overhead costs are necessary for NFPs to serve their causes effectively, and that contributors should use SROI rather than overhead costs to make their decisions [6].

Gneezy et al. (2014) reveals that contributors' overhead aversion is mainly because they are afraid of corruption among those receiving donations, a kind of hypocrisy. Gneezy et al. (2014) does not oppose NFPs trying to persuade contributors to stop being averse to overhead, but recommends NFPs persuade large donors to become seed donors. They said that, by introducing seed contributors, shifts in contributions between NFPs may occur without increasing total contributions by society as a whole, and appears to view increasing total contributions as more desirable than simple shifts in contributions [6].

There are also prior literature about hypocrisy. Yankah (2019) tries to define hypocrisy as violating and ignoring avowed values, positioning hypocrisy as a serious problem [7]. Some organizations avow that their values are promoting public benefit, however, they actually impair welfare, seeking profit. In accordance with the definition by Yankah (2019), these organizations are hypocritical organizations.

Zhao et al. (2020) indicates lack of studies on hypocrisy. Zhao et al. (2020) focuses not on NFPs but profit-oriented entities. Hypocrisy by profit-oriented entities is more investigated than hypocrisy by "not-for-profit" organizations, thus, lack of studies on hypocrisy by "not-for-profit" organizations is serious [8].

Of course, there are a few prior literature on hypocrisy related to business administration. Christensen et al. (2020) tries to go beyond simply normative research approaches on hypocrisy by profit-oriented entity. Certainly, research approaches which are not simply normative will bring new insights. However, Christensen et al. (2020) does not adopt statistical anlysis directly [9]. Jauernig and Valentinov (2019) are about the relationship of hypocrisy and accounting. Because of focuses on this relationship, their research is valuable for accounting scholars. On the other hand, Jauernig and Valentinov (2019) does not adopt statistical anslysis directly, too [10]. Wang and Zhu (2020) are about stakeholders' reactions around profit-oriented entities, though they do not focus on accounting. Wang and Zhu (2020) adopted statistical analysis directly. Statistical analysis make Wang and Zhu (2020) reliable [11]. From the perspective of accounting this paper adds insights on topic which prior literature have not been researching sufficiently, adopting statistical analysis directly.

\section{3- Building a Theory}

SROI is a kind of return on investment (ROI) developed several decades ago in the US. SROI calculates the utility created by a NFP in a monetary amount. It is widely used in the UK to evaluate the extent of impact by an NFP on welfare and efficiency. The traditional SROI guide was translated from English into many languages, including Italian. Traditional SROI defines the net SROI ratio as Equation 1 [12]:

$$
\text { Net SROI Ratio = Net Present Value / Value of Input }
$$

There are two kinds of SROI: evaluative and forecast. The Impact Multiple of Money (IMM) is a new variation of forecast SROI that, unlike traditional SROI, IMM is calculated by a third party outside the NFP. SROI is a useful tool 
for contributors; however, traditional SROI cannot be negative in the traditional SROI guide [12]. Addy et al. (2019), which appears to be the official explanation by the developers of IMM due to the fact that three of its four authors helped develop IMM, does not mention that IMM can be negative, either [13].

To determine whether negative SROI can exist in practice, two problems must be considered: whether SROI can actually be negative, and, if so, whether negative SROI can be reported. Historically, Jevons used the concept of disutility. Ethics in SROI are based on utilitarianism [14]. Utilitarianism is sometimes used in welfare economics, and total welfare in utilitarianism is defined as Equation 2.

$$
\mathrm{W}=\mathrm{U}_{1}(\cdot)+\mathrm{U}_{2}(\cdot)+\ldots+\mathrm{U}_{\mathrm{n}}(\cdot)
$$

$\mathrm{U}_{1}(\cdot)$ represents the welfare of person 1 and all variables are allowed to influence his or her welfare [15]. Bentham, in his systematic consideration of utilitarianism, thought that ethics had to be constructed based on pleasure and pain [16]. Because pain correlates to disutility, utilitarianism is in accordance with the concept of disutility. Thus, introducing the concept of disutility to SROI justifies the existence of negative SROI. When a situation with an organization that calls itself a NFP is 2 and a situation without the organization is 1, net present value is as shown in Equation 3:

Net Present Value $=\mathrm{W}_{2}-\mathrm{W}_{1}$

If Equation 3 is negative, the organization has created disutility. While the concept of disutility may not be wellknown, a few contemporary economists use this concept to consider labor, and at least one economist uses it to consider environmental problems $[17,18]$.

Most executives of organizations that call themselves NFPs may hesitate to announce negative SROI. However, traditional SROI has a process of assurance, and assurance gives reliability to their SROI reports. Because IMM is calculated by people outside the organization, executives' intentions do not influence IMM, making it more reliable. If SROI of a "not-for-profit" organization is negative and profit-oriented, the organization is hypocritical and not actually a NFP, but rather an organization that impairs welfare. The higher the absolute value of negative SROI, the more efficiently such an organization impairs welfare.

The SROI guide allows an alternative calculation, though both the numerator of the return on equity (ROE) and the numerator of return on assets (ROA) are the net amount. This alternative can serve as a loophole to hide negative SROI. This alternative is as in Equation 4 [12]:

\section{SROI Ratio $=$ Present Value $/$ Value of Input}

The numerator of Equation 4 is the gross amount and is not influenced by costs. SROI ratio is higher than the net SROI ratio, making it harder for the SROI ratio to be negative than the net SROI ratio. This alternative should be prohibited in order to abolish loopholes used to hide negative SROI and to prevent contributors from making donations that impair welfare. Although IMM has not been used to the same extent as traditional SROI, it is a more appealing version of SROI. Since prior literature describing how much IMM costs for contributors is scarce, it is difficult to determine what data are required to judge whether calculating negative IMM is practical. Thus, at this stage, a stable step toward maximizing welfare would be for contributors to find a way to prevent receivers of donations from hiding negative SROI. The SROI guide briefly mentions SROI assurance by an independent third party [12]. Verifying whether it is practical to adopt SROI with assurance at organizations receiving contributions may provide contributors with a way to do this.

\section{4- Research Methodology}

This paper uses a questionnaire-based survey, a widely adopted methodology in social science, and was conducted not in Italy but in Japan for economic feasibility. Because housewives control the finances of most Japanese households, the respondents were housewives living in Japan. The age of the respondents was set between 20 and 99 years old.

The respondents were limited to those who have made donations to certified NPO organizations and have viewed their financial statements. Such housewives are sophisticated individual contributors and their answers are reliable. A certified NPO organization is a category of NFP in Japan and include various type of NFPs, such as those that provide aid to the poor and those that support education. The reason this survey limits respondents to contributors to certified NPO organizations is to prevent mixing answers with respondents who contributed to organizations that are not outwardly NFPs. Most certified NPO organizations are legally guaranteed to be outwardly NFPs.

Candidates were asked questions to screen for respondents who meet the prerequisites mentioned above. The sample size was 200 respondents. Questionnaires were distributed and collected in November 2020 through Rakuten Insight. Rakuten Insight is a member of a quality control organization and ensures that no responses are false. 
Respondents had the right to refuse to answer to the questionnaire. All respondents gave permission through informed consent to the authors of this paper to use the results for the improvement of the third sector. Informed consent was obtained through a written statement on respondents' computer screens. All respondents were anonymous to the author.

Main questions (MQs) in questionnaires are as follows:

- Question 1: Approximately how much did you donate to certified NPO organizations on average per year between 2017 and 2019?

- Question 2: Are there any certified NPO organizations that you think are impairing public benefit through their activities?

- Question 3: In relation to the previous question, describe just one factor by which you think the certified NPO organization is impairing public benefit.

- Question 4: A financial ratio called SROI is used throughout the UK to show how efficiently NFPs contributed to public benefit using the contributions they received. Would you look at SROI when you selecting destinations to make donations if executives of certified NPO organizations announced this SROI?

- Question 5: Assurance on SROI is a process in which a third party independent from the executives of a NFP checks whether the SROI the executives announced are correct. What is the maximum percentage of contributions you would allow certified NPO organizations to use on paying for SROI assurance rather than on the mission of the NPO itself?

- Question 6: If a certified NPO organization's overhead cost, which consists of administrative and fundraising costs, occupies large percentage of total costs, do you feel that the organization is misappropriating contributions for purposes that are not its mission?

- Question 7: In relation to the previous question, describe what percentage of overhead cost at an NPO would make you feel that the organization is misappropriating contributions for purposes that are not its mission.

Respondents selected "Yes" or "No" on MQ2, 4, and 6. Only respondents who selected "Yes" on MQ2 were asked to respond MQ3. Only respondents who selected "Yes" on MQ6 were asked to respond MQ7.

This paper uses $\chi^{2}$ test in order to explore relationships between responses on MQ2, 4, and 6. If there is a relationship between $2 \mathrm{MQs}$, this paper also calculates odds ratio (OR) to judge the strength of the relationship. To explore correlations between responses on MQ1, 5, and 7, this paper uses regression analysis. If there is a correlation between responses on MQ1, 5 and 7, this paper also uses $t$-test between responses on these MQs to gain additional information. The flowchart of statistical analysis is as Figure 1.

This paper uses IBM SPSS Statistics, a standard application in social science, as a statistical application because of its reliability. This application makes statistical analysis of raw data, rather than condensed data, possible. Although raw data is maintained in a spreadsheet file, the statistical functions of the spreadsheet were not used in the process of statistical analysis in this paper. Readers can request raw data through the contact information provided in this paper as needed.

\section{5- Results}

\section{5-1- Sample Characteristics}

In order to avoid biases, let's examine sample characteristics of respondents who passed screening questions and proceeded to MQs.

Respondents' ages are as shown in Table 1. Questionnaires were distributed online, and although it is sometimes thought that few elderly people use the internet, respondents included a sufficient percentage of the elderly. The fact that percent of respondents in their 20s is low is not a bias of the survey because most young people in Japan have low salaries and thus few are able to afford to make contributions to certified NPO organizations.

Table 1. Respondents' ages.

\begin{tabular}{ccccccc}
\hline Age & $20 \mathrm{~s}$ & $30 \mathrm{~s}$ & $40 \mathrm{~s}$ & $50 \mathrm{~s}$ & $60 \mathrm{~s}$ & $70 \mathrm{~s}-$ \\
\hline$\%$ & 4.0 & 21.0 & 19.5 & 24.0 & 20.5 & 11 \\
\hline
\end{tabular}




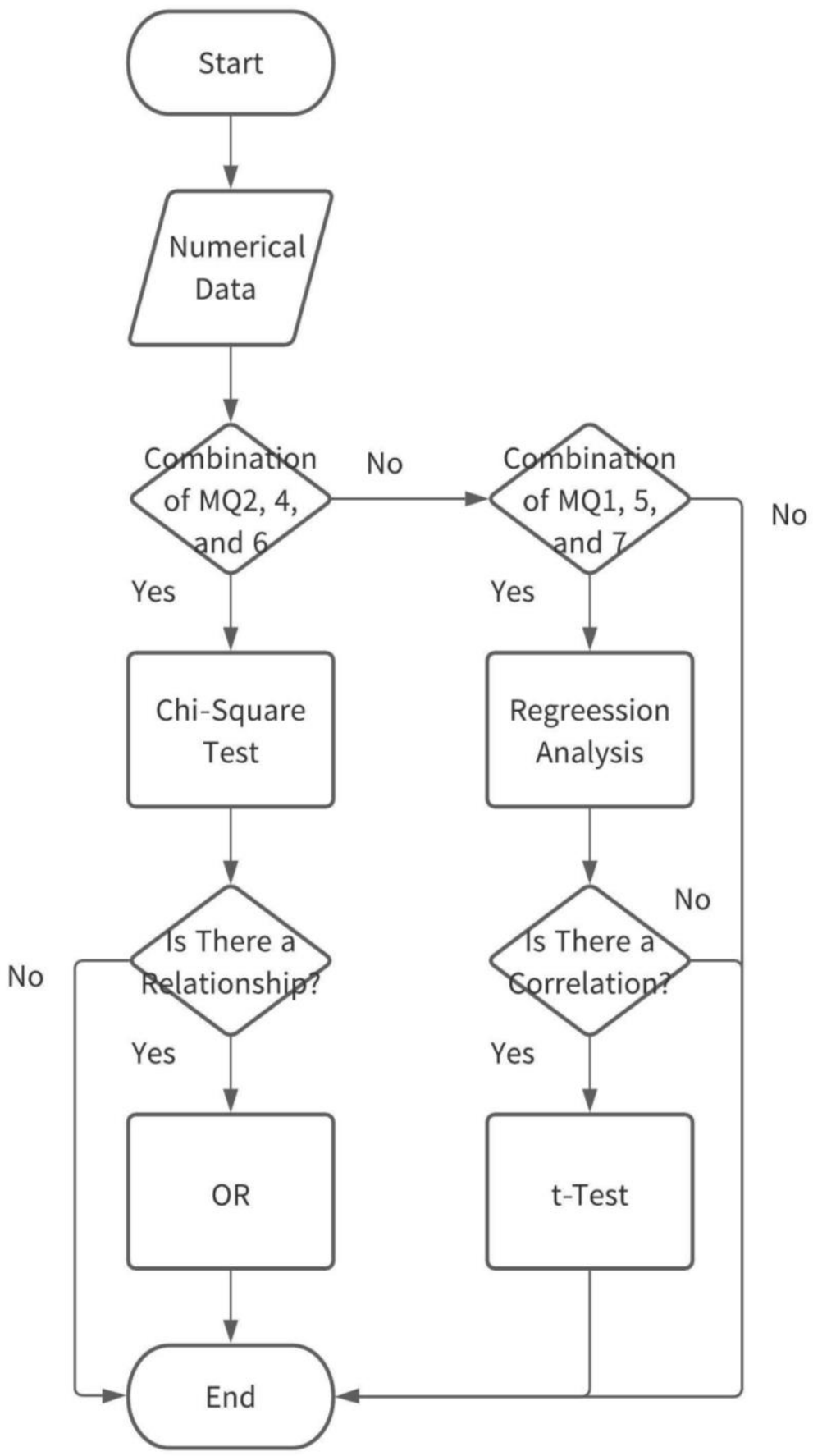

Figure 1. Flowchart of statistical analysis.

Respondents' locations are as shown in Table 2. Unlike Italy, Japan does not have states, but rather prefectures that, along with the national Japanese government, have legal power on the third sector. Regulations on certified NPO organizations vary between prefectures to some extent, meaning that if a high number of respondents come from one particular prefecture, there may be bias in the survey due to prefectural regulations. Tokyo includes the entire metropolitan area of the capital, Osaka includes the city of Osaka, and Kanagawa includes Yokohama. Respondents were not particularly high in any one of these three prefectures. This survey does not contain bias caused by prefectural regulations.

Table 2. Respondents' locations.

\begin{tabular}{ccccc}
\hline Prefecture & Tokyo & Osaka & Kanagawa & Others \\
\hline$\%$ & 14 & 8 & 15 & 63 \\
\hline
\end{tabular}




\section{5-2- Data}

Figure 1 is a scatter diagram between responses on MQ1 and 5. There are three outliers. Most contributors do not make large donations in Japan, as there are few super rich people in Japan. Thus, these dots appear to be responses from contributors who made not normal contributions, but legacies. In order to match conditions, this paper excludes these three outliers, meaning that the sample size is effectively 197 rather than 200.

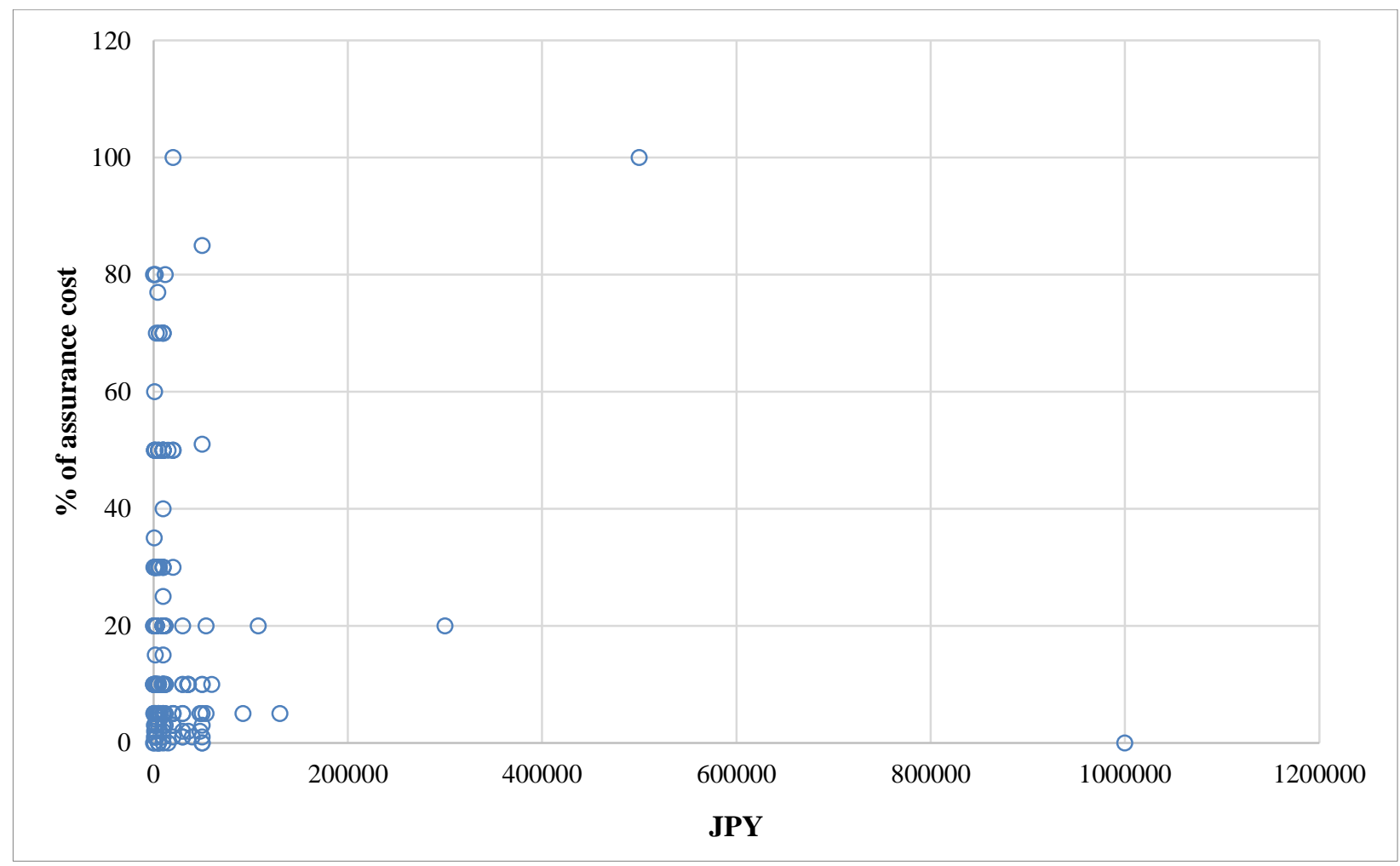

Figure 2. Scatter diagram to find abnormal dots.

Just $17.3 \%$ of responses to MQ2 were "Yes", while 71.1\% of responses to MQ4 were "Yes" and 70.6\% of responses to MQ6 were "Yes".

Responses to MQ3 were divided into clear descriptions and vague descriptions. Descriptions are categorized as in Table 3. Because vague descriptions are difficult to use in this discussion, they have simply categorized as "vague descriptions".

Table 3. Descriptions on MQ3.

\begin{tabular}{lc}
\multicolumn{1}{c}{ Reasons } & Number \\
\hline Profit seeking & 4 \\
Lack of accountability & 5 \\
Insufficient governance system & 3 \\
Waste of money by the organization & 1 \\
Lack of public support & 1 \\
Being essentially a political organization & 1 \\
Mission itself & 10 \\
"Vague description" & 9 \\
\hline \multicolumn{2}{c}{ Total }
\end{tabular}

The average amount given in response to MQ1 was 13,102.60 JPY, while the median was 10,000.00 JPY. The difference between the average and median was neither small nor large. The average response for MQ5 was $19.21 \%$, while the median was $10.00 \%$. The difference between the average and median here was large. The average response to MQ7 was $32.11 \%$, while the median was $30.00 \%$. The difference between the average and median here was small. 


\section{5-3- Statistical Analysis}

The result of the $\chi^{2}$ test between responses to MQ4 and 6 is $\chi^{2}(1, N=197)=17.741, p<0.001$. The null hypothesis that these responses are independent from each other is rejected by this test, showing that there is a relationship between responses on MQ4 and 6. Because residual analysis, which shows the type of relationship, requires at least three items on a row or line of the matrix, it was impossible in this survey, where the number of items for MQ2, 4, and 6 was two. However, 141 of 197 respondents selected the same responses for MQ4 and 6. Thus, it can be said that the type of relationship between responses to MQ4 and 6 is identification.

The OR between responses to MQ4 and 6 was 3.964 [2.047, 7.677], meaning that, because this OR is higher than 1, the relationship between responses to MQ4 and 6 is strong.

The result of the $\chi^{2}$ test between responses to MQ2 and 4 is $\chi^{2}(1, N=197)=0.121, p \geq 0.10$. The null hypothesis that these responses are independent from each other is not rejected by this test, meaning there is no evidence of a correlation. The result of the $\chi^{2}$ test between responses to MQ2 and 6 is $\chi^{2}(1, \mathrm{~N}=197)=0.000, p \geq 0.10$. The null hypothesis is not rejected by this test, meaning there is no evidence of a correlation here, either.

The result of regression analysis between responses to MQ5 and 7 conducted on $n=139$ is $p<0.001$. Thus, there is a correlation between responses to MQ5 and 7. This regression analysis shows $\mathrm{B}=.415$ and $\mathrm{B}$ is positive. Figure 2 is a scatter diagram with a regression line between responses MQ5 and 7. However, this regression analysis also shows $R^{2}$ $=.132$. This $R^{2}$ is low and is not sufficiently suitable for prediction.

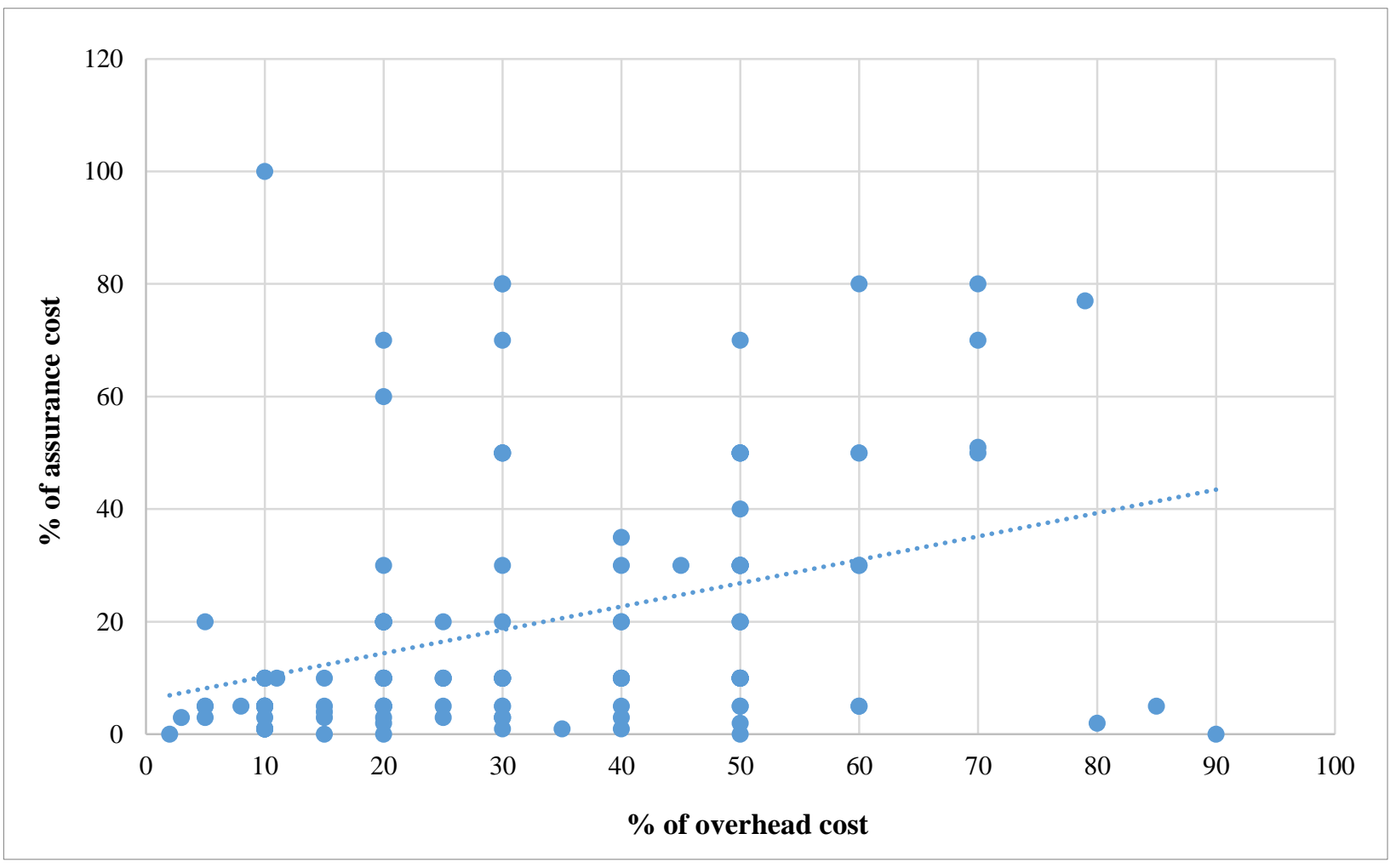

Figure 3. Scatter diagram with regression line.

The result of a $t$-test between responses to MQ 5 and 7 is $\mathrm{t}(138)=6.346, p<0.001$, showing that there is a difference between the averages of responses to MQ5 and 7.

The result of regression analysis between responses to MQ1 and 5 is $p \geq 0.10$. Thus, there is no evidence of correlation between responses to MQ1 and 5. The result of regression analysis between responses to MQ1 and 7 conducted on $\mathrm{n}=139$ is $p \geq 0.10$. Thus, there is no evidence of correlation between responses to MQ1 and 7 .

\section{6- Discussion}

The situation of the third sector is not dire. The results of MQ2 can be interpreted to mean that many contributors do not have experience with "not-for-profit" organizations that impair welfare; nevertheless, such organizations exist. Not all organizations that impair welfare are hypocritical organizations in the definition adopted in this paper. However, responses to MQ3 serve as evidence of the belief that some of "not-for-profit" organizations are hypocritical. As Yankah (2019) insisted, hypocrisy is a serious problem. Even if there are not many hypocritical organizations, there is still a 
problem which should be solved. The results of the $\chi^{2}$ test, counting the same responses, and OR between responses to MQ4 and 6 show what financial ratios contributors will consider in the near future. Contributors who have been looking at overhead cost ratio will also look at SROI if the use of SROI spreads in countries where organizations that are candidates for their donations exist.

However, the result of a regression analysis between responses to MQ5 and 7 shows an obstacle for spreading the use of SROI with assurance. Contributors react to assurance cost similarly to how they react to overhead cost, revealing that contributors who have been strongly opposed to receiving organization spending money on overhead costs would also oppose receiving organization spending money on the cost of assurance, which is part of overhead costs. The percentage of assurance cost respondents would allow is lower than the percent of overhead cost respondents would allow. The result of the $t$-test shows this difference is significant. It was shown clearly that respondents understand the relationship between assurance cost and overhead cost, an understanding that reinforces the reliability of this discovery.

A measure to overcome this obstacle is to convince large contributors to become seed contributors, as Gneezy et al. (2014) suggested [6]. Hypocritical organizations will also be compelled to find seed contributors because of competition with genuine NFPs, even if finding seed contributors does not expand contributions among society as a whole, but merely shifts contributions between receiving organizations. Since introducing seed contributors will prevent overhead aversion, and since contributors regard SROI valuable, pressure from contributors will compel not only genuine NFPs but also hypocritical organizations to adopt SROI with assurance. Hypocritical organization will lose the excuse that contributions received are insufficient for covering assurance costs, making it impossible to hide negative SROI.

Disclosure of SROI with assurance is practical, and will show as negative SROI in hypocritical organizations. SROI with assurance can help contributors distinguish hypocritical organizations from genuine NFPs. Contributors will stop contributing to such hypocritical organizations after looking at their negative SROI, and thus impairment on welfare will decrease. Increasing contributions in society as a whole clearly improve welfare. Avoid contribution to hypocritical organizations and instead contributing to genuine NFPs is included in shifts in contributions to receiving organization. Even Gneezy et al. (2014) does not indicate that shifts in contributions to receiving organization would possibly improve welfare as well [6].

It can be interpreted why there are no evidence of relationships between MQ2 and 4 and between MQ2 and 6. It can be interpreted why there are no evidence of correlations between MQ1 and 5 and between MQ5 and 7, too. Regardless sophisticated contributors think hypocritical organizations exist or do not think, most sophisticated contributors probably want to look at SROI in order to select one or several better NFPs from many good NFPs at least. Thus, the result that there is no evidence of relationship between MQ2 and 4 is unsurprising. Some contributors may pick up only excellent NFPs as candidates of receivers and look only at financial information of these NFPs. Such contributors probably do not encounter extreme high overhead cost ratio, being cautious of extreme high overhead cost ratio. It is possible that they trust in the entire third sector as the result. Thus, the result that there is no evidence of relationship between MQ2 and 4 is permissible.

Shareholders of profit-oriented entities aim to receive dividends. Thus, the more shareholders buy stocks, the more shareholders may have economic incentives to care about financial ratios. NFPs cannot make dividends and contributors do not have such economic incentives. Hence, contributors cannot economically collect principles of their contributions different from shareholders of profit-oriented entities. Thus, sophisticated contributors may select receivers carefully regardless of amounts of their contributions. Thus, the result that there are no evidence of relationships between MQ1 and 5 and between MQ5 and 7 is also permissible. Because this paper adopts not only a narrative method but also statistical analysis, these explanations and interpretations can be reliable like Wang and Zhu (2020).

\section{7- Conclusion}

Theoretically, it is possible to calculate negative SROI. If SROI with assurance spreads, executives of hypocritical organizations will no longer be able to hide negative SROI. According to statistical analysis, disclosure of SROI with assurance is practical. Spreading SROI with assurance will trigger shifts from contributions to hypocritical organizations to contributions to genuine NFPs. This shift in receiving organization would possibly improve welfare as well. This interpretation on the shift in contributions serves as a kind of hint that may be generalized to have meaning in a wide range of academic research on NFPs and in their practice, although it is not the main conclusion of this paper, but rather a by-product.

There are also some limitations to this paper. The first is that experiments were not performed on SROI with assurance. Such experiments may bring accounting scholars some insight. Another limitation is that sample size was limited, as there are fewer contributors in Japan than in countries where NFPs flourish. Questionnaire-based surveys in such countries may bring accounting scholars more robust insight than this paper. Still, the main conclusion that SROI with assurance can help contributors distinguish hypocritical organizations from genuine NFPs is useful in guiding stakeholders. 


\section{8- Declarations}

\section{8-1-Data Availability Statement}

The data presented in this study are available on request from the corresponding author.

\section{8-2-Funding}

The author(s) received no financial support for the research, authorship, and/or publication of this article.

\section{8-3-Acknowledgements}

This paper is based on an oral presentation by the same author at ECONALANYA 2019 in Turkey.

\section{8-4- Conflicts of Interest}

The author declares that there is no conflict of interests regarding the publication of this manuscript. In addition, the ethical issues, including plagiarism, informed consent, misconduct, data fabrication and/or falsification, double publication and/or submission, and redundancies have been completely observed by the authors

\section{9- References}

[1] Mankiw, N. Gregory. "Principles of Economics.” Eighth Edition. Cengage Learning (2016).

[2] Poverty, Inc. DVD, directed by Michael Matheson Miller (Its publication location is only disclosed as in the U.S.: This film is not from an incorporated publisher, 2014).

[3] Green, L, K Ashton, M Dyakova, and L Parry-Williams. "Adding Value to the Use of Health Impact Assessment and Social Return on Investment Technologies." European Journal of Public Health 30, no. Supplement_5 (September 1, 2020). doi:10.1093/eurpub/ckaa166.341.

[4] Bellucci, Marco, Carmela Nitti, Serena Franchi, Enrico Testi, and Luca Bagnoli. "Accounting for Social Return on Investment (SROI): The Costs and Benefits of Family-Centred Care by the Ronald McDonald House Charities." Social Enterprise Journal 15, no. 1 (February 4, 2019): 46-75. doi:10.1108/sej-05-2018-0044.

[5] McElwee, Gerard, and Robert Smith. "Towards a Nuanced Typology of Illegal Entrepreneurship: A Theoretical and Conceptual Overview.” Contemporary Issues in Entrepreneurship Research (May 22, 2015): 3-22. doi:10.1108/s2040-724620150000005018.

[6] Gneezy, U., E. A. Keenan, and A. Gneezy. “Avoiding Overhead Aversion in Charity.” Science 346, no. 6209 (October 30, 2014 ): 632-635. doi:10.1126/science.1253932.

[7] Yankah, Ekow N. "Legal Hypocrisy.” Ratio Juris 32, no. 1 (February 21, 2019): 2-20. doi:10.1111/raju.12234.

[8] Zhao, Hongdan, Jing Xu, Yuanhua Chen, and Wenyuan Sun. "The Employee Attributions of Corporate Hypocrisy in Corporate Social Responsibility: An Explore Research Based on Grounded Theory.” SAGE Open 10, no. 2 (April 2020): 215824402092442. doi:10.1177/2158244020924427.

[9] Christensen, Lars Thøger, Mette Morsing, and Ole Thyssen. "Timely Hypocrisy? Hypocrisy Temporalities in CSR Communication.” Journal of Business Research 114 (June 2020): 327-335. doi:10.1016/j.jbusres.2019.07.020.

[10] Jauernig, Johanna, and Vladislav Valentinov. "CSR as Hypocrisy Avoidance: a Conceptual Framework." Sustainability Accounting, Management and Policy Journal 10, no. 1 (March 4, 2019): 2-25. doi:10.1108/sampj-05-2018-0141.

[11] Zhigang, Wang, and Zhu Haoming. "Consumer Response to Perceived Hypocrisy in Corporate Social Responsibility Activities." SAGE Open 10, no. 2 (April 2020): 215824402092287. doi:10.1177/2158244020922876.

[12] Nicholls, Jeremy, Eilis Lawlor, Eva Neitzert, Tim Goodspeed, and S. Cupitt. "A Guide to Social Return on Investment: The SROI Network." Accounting for Value (2012).

[13] Addy, Chris, Maya Chorengel, Mariah Collins, and Michael Etzel. "Calculating the Value of Impact Investing an Evidencebased Way to Estimate Social and Environmental Returns." Harvard Business Review 97, no. 1 (2019): 102-109.

[14] Maier, Florentine, Christian Schober, Ruth Simsa, and Reinhard Millner. "SROI as a Method for Evaluation Research: Understanding Merits and Limitations." VOLUNTAS: International Journal of Voluntary and Nonprofit Organizations 26, no. 5 (September 9, 2014): 1805-1830. doi:10.1007/s11266-014-9490-х.

[15] Bojer, Hilde. "Distributional Justice: Theory and Measurement.” Routledge (2003).

[16] Schofield, Philip. "Bentham: A Guide for the Perplexed." Continuum (2009).

[17] Spencer, David. "Love's labor's lost? The disutility of work and work avoidance in the economic analysis of labor supply." Review of Social Economy 61, no. 2 (2003): 235-250. doi:10.1080/0034676032000098237.

[18] Farajzadeh, Zakariya. "Emissions Tax in Iran: Incorporating Pollution Disutility in a Welfare Analysis." Journal of Cleaner Production 186 (June 2018): 618-631. doi:10.1016/j.jclepro.2018.03.093. 